\title{
REVIEW
}

\section{Advances in the genetics of endometriosis}

\author{
Erica C Dun, Robert N Taylor and Fritz Wieser*
}

\begin{abstract}
Endometriosis is a gynecological disease characterized by implantation of endometrial tissue outside of the uterus. Early familial aggregation and twin studies noted a higher risk of endometriosis among relatives. Studies on the roles of the environment, genetics and aberrant regulation in the endometrium and endometriotic lesions of women with endometriosis suggest that endometriosis arises from the interplay between genetic variants and environmental factors. Elucidating the hereditary component has proven difficult because multiple genes seem to produce a susceptibility to developing endometriosis. Molecular techniques, including linkage and genome-wide analysis, have identified candidate genes located near known loci related to development and regulation of the female reproductive tract. As new candidate genes are discovered and hereditary pathways identified using technologies such as genome-wide analysis, the possibility of prevention and treatment becomes more tangible for millions of women affected by endometriosis. Here, we discuss the advances of genetic research in endometriosis and describe technologies that have contributed to the current understanding of the genetic variability in endometriosis, variability that includes regulatory polymorphisms in key genes.
\end{abstract}

\section{Introduction}

The complete sequencing of the human genome in 2001 revolutionized the molecular era of human disease [1]. Of the 3 billion chemical bases comprising the 46 human chromosomes, approximately 30,000 genes have been mapped. For complex human conditions, such as type 2 diabetes mellitus, coronary artery disease and endometriosis, the allelic architectures are difficult to characterize because they fail to show classic Mendelian

*Correspondence: fwieser@emory.edu

Department of Gynecology and Obstetrics, Emory University School of Medicine, Atlanta, GA 30322, USA inheritance. Multifactorial or polygenic disorders, such as endometriosis, are determined by multiple genes with allelic variations. Early studies by the groups of Simpson and Lamb [2,3] suggested that endometriosis has a heritable component.

Endometriosis is a common, chronic, inflammatory and estrogen-dependent gynecological disease that develops as a consequence of a combination of genetic predisposition and environmental factors. It affects 10 to $15 \%$ of women in their reproductive years [4] and is characterized by the implantation of endometrial (womb lining) tissue outside of the uterus (ectopic endometrium). Common locations of ectopic endometrial implantation are the pelvic peritoneum, ovaries, bowel, bladder, and less frequently, the pleural cavity, liver and kidneys.

Endometriosis is diagnosed in 30 to $40 \%$ of women with infertility and pelvic pain [5]. Women frequently experience symptoms of dysmenorrhea (painful menstruation), dyspareunia (pain during sexual intercourse), dysuria (pain during urination) and dyschezia (difficulty with defecating). The severity of the disease is graded on a scale of I to IV by the revised American Fertility Society classification system [6], which quantifies disease according to the amount of ectopic endometrial tissue present, its location and the amount of scarring in the pelvis. Stages I and II are described as minimal to mild and stages III and IV are described as moderate to severe [6]. Endometriosis accounts for $\$ 22$ billion annually in total US healthcare costs [7]. Medical treatments are often of limited efficacy, counterproductive to fertility and can cause untoward side effects owing to suppression of endogenous steroid hormone levels. Regardless of treatment, endometriotic lesions recur in more than $30 \%$ of patients with reduced fecundity and pelvic pain [8]. Women with endometriosis who have pelvic pain have an increased risk of several conditions, including allergies, asthma, autoimmune diseases, hypothyroidism and chronic fatigue syndrome [8].

\section{Familial aggregation and twin studies}

Beginning in the 1940s, research into the cause of endometriosis included multiple reports of affected relatives, suggesting a familial occurrence $[9,10]$. In a 1971 questionnaire study of 350 women with endometriosis, $22.4 \%$ of the respondents reported a first- or second-degree relative 
with endometriosis [11]. Simpson et al. [2] published the first formal genetic studies on women with histologically proven endometriosis in 1980. In this study, he found that $6.9 \%$ of first-degree relatives also had endometriosis; by contrast, less than $1 \%$ of their husbands' female relatives had endometriosis [2]. In a follow-up study by Malinak et al. [12], the clinical characteristics of patients with histologically confirmed pelvic endometriosis who had affected relatives were compared with patients who had endometriosis without affected relatives. The primary difference was the finding that women who had relatives with endometriosis had more severe disease, defined as stages III to IV. The result further supported the role of genetics in the pathophysiology of endometriosis and established a 7\% risk of developing endometriosis for first-degree relatives. Lamb et al. [3] later estimated an overall risk of $1.9 \%$ for second-degree relatives. In subsequent familial aggregation studies in the UK, Coxhead and Thomas [13] compared 64 women with laparoscopically confirmed endometriosis and 128 controls and found that $9.4 \%$ of the patients had firstdegree relatives with endometriosis, yet only $1.6 \%$ in the control group had relatives with endometriosis. They found a sixfold increased risk for first-degree relatives of women with laparoscopically confirmed diagnosis of endometriosis. Moen and Magnus [14] conducted a large Norwegian study composed of 522 cases, which supported the findings of earlier studies looking at familial aggregation; $3.9 \%$ of mothers and $4.8 \%$ of sisters of affected individuals had endometriosis compared with only $0.6 \%$ of sisters in the control group. Interestingly, this Norwegian study [14] also concluded that symptom severity was increased among women who had relatives with endometriosis, a conclusion originally reported in a smaller study by Malinak et al. [12].

Icelandic people, who have been geographically and genetically isolated, have been an interesting population in which to study familial aggregation. A computerized database includes all 283,000 presently living Icelanders in addition to most of their ancestors since the island was settled in the late 9th century. Stefansson et al. [15] used this database to study women diagnosed with endometriosis over a 12-year period (1981 to 1993). They calculated the contribution of genetic factors by comparing average kinship coefficients. The calculated kinship coefficient in 750 women with endometriosis was $1.82 \times 10^{-4}$, which was significantly higher $(P<0.001)$ than that of matched controls $\left(1.45 \times 10^{-4}\right)$.

Twin studies have been used to discern the separate contributions of genes and environment. A small Norwegian twin trial reported that six of eight monozygotic twin pairs were concordant for endometriosis [16]. Hadfield et al. [17] described concordance in 9 out of 16 monozygotic pairs for stage III to IV endometriosis in a larger British population of twin pairs. Of the seven discordant pairs, there were five pairs in which one twin had stage I to II disease and the other had stage III to IV disease. Interestingly, the women in the two discordant monozygotic twin pairs were all infertile. The observation suggests that genes associated with the development of endometriosis may be linked to genes that cause infertility.

\section{Linkage analysis studies}

Linkage analysis has been an important technique for discovering the chromosomal location of disease-related genes. Many monogenetic Mendelian disorders, including mutations in the familial breast and ovarian cancer genes BRCA1 and BRCA2, have been successfully mapped using linkage analysis $[18,19]$. This technique has been used for detection of genetic markers of endometriosis. A large linkage study by Treloar et al. [20] combined Australian and UK families and genotyped 4,985 women, including 2,709 with endometriosis. The collaborative International Endogene Study [20] brought together two independent groups: the UK-based Oxford Endometriosis Gene Study and the Australian Genes behind Endometriosis Study. The study [20] used linkage analysis techniques to find two loci of significant linkage on chromosome 10q26 and another region of suggestive linkage on chromosome 20p13. Chromosome 10q26 had previously been implicated in a candidate gene study [21] that reported aberrant endometrial $E M X 2$ expression in women with endometriosis. EMX2 encodes a transcription factor required for reproductive-tract development [22], but variants of $E M X 2$ have not been confirmed to contribute to the development of endometriosis [23]. Although promising, linkage analysis has yielded few significant genetic markers [24].

\section{Genetic association studies}

Candidate genes are chosen on the basis of their pathophysiological relevance and variants of candidate genes are assessed in samples of endometriosis cases and controls. Table 1 summarizes the most commonly studied candidate genes. Generally, candidate genes can be divided into several classes: genes involved in regulating xenobiotic metabolism, those involved in steroid action and receptors, and those involved in inflammatory or angiogenic responses (Table 1) [25].

Human endometrium, whether in its normal place (eutopic) or ectopic, is a hormone-responsive tissue, which also produces steroids, including estrogen, that have been shown to promote endometriosis [26]. Risk factors of endometriosis include prolonged exposure to endogenous estrogen, such as that resulting from early menarche or late menopause, and exogenous estrogens. Dysregulation of progesterone signaling in the eutopic 
Table 1. Commonly reported endometriosis candidate genes from association studies

\begin{tabular}{|c|c|c|c|c|c|}
\hline Process regulated & Candidate gene & $\begin{array}{c}\text { Gene } \\
\text { symbol }\end{array}$ & $\begin{array}{c}\text { Chromosomal } \\
\text { locus }\end{array}$ & $\begin{array}{l}\text { Number } \\
\text { of positive } \\
\text { studies }\end{array}$ & $\begin{array}{c}\text { Number } \\
\text { of negative } \\
\text { studies }\end{array}$ \\
\hline \multirow[t]{4}{*}{ Xenobiotic metabolism } & Glutathione M-transferase 1 & GSTM1 & $1 \mathrm{p} 13.3$ & 9 & 12 \\
\hline & Glutathione S-transferase 1 & GSTT1 & $22 q 11.2$ & 7 & 7 \\
\hline & $\mathrm{N}$-acetyl-transferase 2 & NAT2 & $8 p 22$ & 1 & 4 \\
\hline & Aryl hydrocarbon receptor repressor & AHRR & $5 p 15$ & 3 & 1 \\
\hline \multirow[t]{6}{*}{ Hormone receptors or metabolism } & Estrogen receptor a & ESR1 & $6 q 24-27$ & 8 & 3 \\
\hline & Progesterone receptor & $P R$ & $11 q 22-33$ & 4 & 2 \\
\hline & Cytochrome P450, family 17 , subfamily A, polypeptide 1 & CYP17A1 & $10 q 24$ & 3 & 6 \\
\hline & Cytochrome P450, family 19 , subfamily A, polypeptide 1 & CYP19A1 & $15 q 21$ & 5 & 2 \\
\hline & Cytochrome P450, family 1, subfamily A, polypeptide 1 & CYP1A1 & $15 q 24$ & 1 & 3 \\
\hline & Hydroxysteroid (17- $\beta$ ) dehydrogenase 1 & HSD17B1 & $17 q 11-21$ & 3 & 0 \\
\hline \multirow[t]{5}{*}{ Inflammation or angiogenesis } & Tumor necrosis factor a & TNFA & $6 p 21.3$ & 2 & 7 \\
\hline & Interleukin-6 & IL-6 & $7 p 15.3$ & 4 & 4 \\
\hline & Interleukin-10 & IL-10 & $1 q 31-32$ & 7 & 0 \\
\hline & Vascular endothelial growth factor A & VEGFA & $6 p 21-12$ & 5 & 1 \\
\hline & Intercellular adhesion molecule 1 & ICAMI & $19 \mathrm{p} 13$ & 2 & 3 \\
\hline \multirow[t]{3}{*}{ Other processes } & Galactose-1-phosphate uridyl transferase & GALT & $9 \mathrm{p} 13$ & 2 & 2 \\
\hline & Tumor suppressor p53 & TP53 & $17 p 13$ & 2 & 7 \\
\hline & HLA class II histocompatibility antigen, DRB1-9 $\beta$ chain & HLA-DRB1 & $6 p 21$ & 3 & 4 \\
\hline
\end{tabular}

Association studies in English on the most commonly studied candidate genes were identified by performing a PubMed literature search up to 23 June 2010 . If a published study identified one or more positive associations, we identified this study as positive, otherwise negative. Variants of the ESR2, peroxisome proliferatoractivated receptor $\gamma 2$ (PPAR- $\gamma 2$ ), nuclear factor KB1 (NFKB1), E-cadherin, matrix metalloproteinase 1 (MMP1), MMP9, cyclin dependent kinase inhibitor p27 (CDKN1B), neurokinin-1 (TAC1),nitric oxide synthase 3 (NOS3), fibroblast growth factor 1 (FGF1), FGF2 and catechol-O-methyltransferase (COMT) genes have also been investigated as candidate genes potentially associated with endometriosis.

and ectopic endometrium leads to impaired physiological functions, including infertility and endometriosis in women [27-29].

Several association studies on single nucleotide polymorphisms (SNPs) of steroid receptor genes and steroid metabolizing genes and endometriosis have been performed. Results on the association of estrogen receptor polymorphisms and endometriosis are inconsistent. Some studies showed an association of a polymorphism $(P v u I I)$ in the estrogen receptor 1 (ESR1) and endometriosis [30,31], whereas other studies did not support this association [32,33]. These inconsistencies are probably caused by ethnic differences and small sample size of association studies. Huber et al. [34] analyzed the genotype frequencies of ten estrogen-metabolizing SNPs in patients with endometriosis compared with controls. Of these, the vIV $A \rightarrow C$ variant in the hydroxysteroid (17- $\beta$ ) dehydrogenase 1 (HSD17B1) gene was significantly associated with an increased risk of endometriosis in both univariate and multivariate analyses.

Insensitivity to progesterone has been suggested to affect both implantation and inflammation in endometriosis [26]. The PROGINS polymorphism identified in the progesterone receptor $(P R)$ gene contributes to growth dysregulation in hormone-sensitive tissues and has been associated with breast and ovarian cancer [35]. The receptor change caused by the PROGINS mutation is hypothesized to affect ligand- and hormone-binding properties, leading to inadequate control of estrogenreceptor-driven proliferation and estrogen overactivation. The PROGINS polymorphism is found more frequently in women diagnosed with endometriosis [36-38], but data using genetic variants in the $P R$ gene to predict endometriosis are inconclusive in various ethnic populations [35,39].

Polymorphisms in cytokine genes, including tumor necrosis factor $(T N F)-\alpha$, interleukin $(I L)-1 \beta, I L-6$ and $I L-10$, and their receptors ( $I L-1 R N$ and $I L-2 R \beta)$, have been extensively studied because of the involvement of cytokines in the pathogenesis of endometriosis [40]; however, genetic variants of cytokine genes have not always shown an association with endometriosis. For example, several studies have reported that polymorphisms in the promoter region of the TNF- $\alpha$ gene do not influence endometriosis risk in Korean, Taiwanese or Caucasian women [41-43]. Similarly, inconsistent findings on the association of genetic variants and endometriosis have been shown for $I L-6$ and intercellular adhesion molecule 1 (ICAM1) genes [44]. 
Exposures to endocrine-disrupting chemicals, such as dioxin, have been implicated in the pathogenesis of endometriosis in rhesus macaques [45] and in women [46,47]. Glutathione $S$-transferases (GSTs) are enzymes involved in the detoxification of a broad range of toxic compounds and carcinogens, including dioxin [48]. Two of the most studied SNPs in detoxification enzymes are in the GST genes GSTM1 and GSTT1, which are located on chromosome $1 \mathrm{p} 13.3$ and 22q11.2, respectively. A meta-analysis by Guo [49] involving 14 studies on GSTM1 and 9 studies on GSTT1 concluded that there was no increased risk for women with the GSTM1 null genotype and a slightly increased risk for those with a GSTT1 polymorphism.

Table 1 summarizes the variable results of the endometriosis and gene polymorphism association studies. These discrepancies may be due to methodological problems, including relatively small numbers of cases and controls and selection of control populations [44]. Another explanation may be the use of different genotyping techniques. In addition, there is difficulty controlling environmental factors and problems replicating results among different ethnic populations. Large, multicenter prospective cohort studies with DNA genotyping arrays and gene-gene and gene-environment studies of endometriosis are needed.

\section{Genome-wide association studies}

High-resolution genomic tools enabling genome-wide association studies (GWASs) [50] offer the prospect of making real progress in the discovery of genes contributing to risk of multi-factorial diseases such as endometriosis. GWASs have been performed successfully in the discovery of new genomic regions that are associated with multifactorial diseases [51,52]. The methodology examines variation across the genome using computational models to compare the genotypes of people with and without disease to identify SNPs associated with disease. Sufficient power using this approach necessitates thousands of subjects, but this can be achieved by collaboration of large consortia. The advantage of this method is that hundreds of thousands of SNPs can be quickly examined for potential associations [53]. Another advantage of GWASs is that they are unbiased and do not depend on biologically plausible candidate genes or specific polymorphisms [54]. Disadvantages are that very large sample sizes are necessary to derive meaningful and reproducible conclusions valuable for characterizing polygenic diseases such as endometriosis.

Several large population-based prospective cohorts in the United States, Europe, Australia and Japan have gathered endometriosis data and represent potential sources for GWASs. These include the American California Teacher Study [55], the Nurses' Health Study II $[56,57]$, the National Health and Nutrition Examination
Survey [58], the French E3N Cohort study [59], the Australian Genes behind Endometriosis Study [60], the Oxford Endometriosis Gene Study [61], the Icelandic Endometriosis Cohort Study [15] and the BioBank Japan project [62]. From these different cohorts, extensive time-dependent covariate data have been collected [56]. The cohorts differ in prevalence of current infertility, surgical diagnosis, age distribution, selection of controls and ethnicity. The first large endometriosis GWAS was published by Uno et al. [63] using the endometriosis cohort from the Biobank Japan project (1,907 Japanese endometriosis cases and 5,292 controls). They identified an association of endometriosis with the SNP rs10965235 located in the cyclin-dependent kinase inhibitor 2B antisense RNA (CDKN2BAS) gene on chromosome 9p21 (with an odds ratio of 1.44) and with rs16826658m in the linkage disequilibrium block that includes the signaling gene WNT4 on chromosome 1p36 [63]. WNT4 signaling has a role in the coordination of female ovarian follicle development and of the development of the fallopian tubes and uterus from the Müllerian (paramesonephric) ducts [64]. CDKN2BAS regulates the expression of $C D K N 2 A$, a cell-cycle kinase inhibitor that controls endometrial proliferation and has been attributed with a role in endometriosis [65].

Interestingly, this GWAS [63] has confirmed loci such as $9 \mathrm{p} 21$ that are shared with conditions previously thought to be unrelated to endometriosis, including coronary artery disease. Recent studies have revealed that genetic variants in 9p21 are associated with multifactorial diseases, including coronary artery disease, type 2 diabetes, malignant melanoma, basal cell carcinoma, nevi (moles) and glioma [66-69]. The clinical relevance of identified genetic variants for predicting risk of endometriosis is unclear because the overall increase in risk caused by the known variants is small [70]. However, GWASs represent a new frontier in the investigation of gene-gene and gene-environment interactions. Predictive power may improve as more susceptibility loci are identified and new computational tools are applied.

\section{Conclusions}

We have seen progress in the understanding of endometriosis in the past decade through linkage analysis and association studies. However, the pathophysiology and genetics of endometriosis are still unclear. The longterm goals in discovering the genetic basis of endometriosis are early detection and improved treatment of endometriosis-associated symptoms, including infertility and pelvic pain. GWASs may bring insight into geneenvironment interaction and identify candidate genes that are associated with endometriosis. This promising new technology has the potential for finding modest associations for polygenic diseases such as endometriosis. 
However, GWASs are prone to error and bias arising from the predominantly case-control study design and the difficulty of interpreting statistics that result from multiple hypothesis testing. They need to be further validated through replication studies that find similar associations among independent samples with large, appropriately powered populations. The credibility and validity of GWASs will be further increased when consistent statistical results are combined with evidence of biological functionality for the variants found. Thereafter, data from GWASs could be used to assess individual risk for endometriosis and may be useful in counseling women for early treatment in order to avoid sequelae such as infertility. In addition, GWAS discoveries could be implemented in the development of novel therapies for the treatment of endometriosis. Genetics-based diagnostic tests for endometriosis and genetically targeted therapies hold the promise to diagnose and treat women at a younger age and allow physicians to better advise women regarding prognosis.

\section{Abbreviations}

EMX2, empty spiracles homeobox 2; GST, glutathione S-transferase; GWAS, genome-wide association study; IL, interleukin; SNP, single nucleotide polymorphism; TNF, tumor necrosis factor.

\section{Competing interests}

The authors declare that they have no competing interests.

\section{Authors' contributions}

ED drafted the manuscript. FW drafted and edited the manuscript. RNT advised on the manuscript content and relevance and edited the manuscript.

\section{Authors' information}

ED is Associate, Department of Gynecology and Obstetrics, Emory University. FW is Assistant Professor, Division of Reproductive Endocrinology and Infertility, Department of Gynecology and Obstetrics, Emory University. His research interests are the pathogenesis of endometriosis, in vitro and in vivo models of endometriosis and anti-inflammatory mechanisms and novel therapies for endometriosis. RNT is Leach-Hendee Professor, Division of Reproductive Endocrinology and Infertility, Department of Gynecology and Obstetrics, Emory University. His research interests are the cellular and molecular biology of endometriosis, novel therapeutic targets and potential medications for the treatment of endometriosis.

Published: 14 October 2010

\section{References}

1. Venter JC, Adams MD, Myers EW, Li PW, Mural RJ, Sutton GG, Smith HO, Yandell M, Evans CA, Holt RA, Gocayne JD, Amanatides P, Ballew RM, Huson DH, Wortman JR, Zhang Q, Kodira CD, Zheng XH, Chen L, Skupski M, Subramanian G, Thomas PD, Zhang J, Gabor Miklos GL, Nelson C, Broder S, Clark AG, Nadeau J, McKusick VA, Zinder N, et al:: The sequence of the human genome. Science 2001, 291:1304-1351.

2. Simpson JL, Elias S, Malinak LR, Buttram VC Jr: Heritable aspects of endometriosis. I. Genetic studies. Am J Obstet Gynecol 1980, 137:327-331.

3. Lamb K, Hoffmann RG, Nichols TR: Family trait analysis: a case-control study of 43 women with endometriosis and their best friends. Am J Obstet Gynecol 1986, 154:596-601.

4. Giudice LC, Kao LC: Endometriosis. Lancet 2004, 364:1789-1799.

5. Barnhart K, Dunsmoor-Su R, Coutifaris C: Effect of endometriosis on in vitro fertilization. Fertil Steril 2002, 77:1148-1155.

6. Revised American Society for Reproductive Medicine classification of endometriosis: 1996. Fertil Steril 1997, 67:817-821.

7. Simoens $S$, Hummelshoj L, D'Hooghe T: Endometriosis: cost estimates and methodological perspective. Hum Reprod Update 2007, 13:395-404.
8. Sinaii N, Cleary SD, Younes N, Ballweg ML, Stratton P: Treatment utilization for endometriosis symptoms: a cross-sectional survey study of lifetime experience. Fertil Steril 2007, 87:1277-1286.

9. Frey $\mathrm{GH}$ : The familial occurrence of endometriosis; report of five instances and review of the literature. Am J Obstet Gynecol 1957, 73:418-421.

10. Gardiner GH, Greene RR, Ranney B: The histogenesis of endometriosis: recent contributions. Obstet Gynecol 1953, 1:615.

11. Ranney B: Endometriosis. IV. Hereditary tendency. Obstet Gynecol 1971, 37:734-737.

12. Malinak LR, Buttram VC Jr, Elias S, Simpson JL: Heritage aspects of endometriosis. II. Clinical characteristics of familial endometriosis. Am J Obstet Gynecol 1980, 137:332-337.

13. Coxhead D, Thomas EJ: Familial inheritance of endometriosis in a British population: a case-control study. J Obstet Gynecol 1993, 13:42-44.

14. Moen MH, Magnus P: The familial risk of endometriosis. Acta Obstet Gynecol Scand 1993, 72:560-564.

15. Stefansson $H$, Geirsson RT, Steinthorsdottir $V$, Jonsson H, Manolescu A, Kong A, Ingadottir G, Gulcher J, Stefansson K: Genetic factors contribute to the risk of developing endometriosis. Hum Reprod 2002, 17:555-559.

16. Moen MH, Schei B: Epidemiology of endometriosis in a Norwegian county. Acta Obstet Gynecol Scand 1997, 76:559-562.

17. Hadfield RM, Mardon HJ, Barlow DH, Kennedy SH: Endometriosis in monozygotic twins. Fertil Steril 1997, 68:941-942.

18. Wooster R, Neuhausen SL, Mangion J, Quirk Y, Ford D, Collins N, Nguyen K, Seal S, Tran T, Averill D, et al:: Localization of a breast cancer susceptibility gene, BRCA2, to chromosome 13q12-13. Science 1994, 265:2088-2090.

19. Hall NR, Fish DE, Hunt N, Goldin RD, Guillou PJ, Monson JR: Is the relationship between angiogenesis and metastasis in breast cancer real? Surg Oncol 1992, 1:223-229.

20. Treloar SA, Wicks J, Nyholt DR, Montgomery GW, Bahlo M, Smith V, Dawson G, Mackay IJ, Weeks DE, Bennett ST, Carey A, Ewen-White KR, Duffy DL, O'Connor DT, Barlow DH, Martin NG, Kennedy SH. Genomewide linkage study in 1,176 affected sister pair families identifies a significant susceptibility locus for endometriosis on chromosome 10q26. Am J Hum Genet 2005, 77:365-376.

21. Daftary GS, Taylor HS: EMX2 gene expression in the female reproductive tract and aberrant expression in the endometrium of patients with endometriosis. J Clin Endocrinol Metab 2004, 89:2390-2396.

22. Du H, Taylor HS: Molecular regulation of mullerian development by Hox genes. Ann N Y Acad Sci 2004, 1034:152-165.

23. Treloar SA, Zhao ZZ, Le L, Zondervan KT, Martin NG, Kennedy S, Nyholt DR, Montgomery GW: Variants in EMX2 and PTEN do not contribute to risk of endometriosis. Mol Hum Reprod 2007, 13:587-594.

24. Kennedy S: Genetics of endometriosis: a review of the positional cloning approaches. Semin Reprod Med 2003, 21:111-118.

25. Taylor RN, Lebovic DI: Endometriosis. In Yen and Jaffe's Reproductive Endcrinology. 6th edition. Edited by Barbieri S. Philadelphia: Saunders Elsevier; 2009;577-596.

26. Bulun SE, Cheng YH, Pavone ME, Xue Q, Attar E, Trukhacheva E, Tokunaga H, Utsunomiya H, Yin P, Luo X, Lin Z, Imir G, Thung S, Su EJ, Kim JJ: Estrogen receptor-beta, estrogen receptor-alpha, and progesterone resistance in endometriosis. Semin Reprod Med 2010, 28:36-43.

27. Fang Z, Yang S, Lydon JP, DeMayo F, Tamura M, Gurates B, Bulun SE: Intact progesterone receptors are essential to counteract the proliferative effect of estradiol in a genetically engineered mouse model of endometriosis. Fertil Steril 2004, 82:673-678.

28. Aghajanova L, Velarde MC, Giudice LC: The progesterone receptor coactivator Hic-5 is involved in the pathophysiology of endometriosis. Endocrinology 2009, 150:3863-3870.

29. Burney RO, Talbi S, Hamilton AE, Vo KC, Nyegaard M, Nezhat CR, Lessey BA, Giudice LC: Gene expression analysis of endometrium reveals progesterone resistance and candidate susceptibility genes in women with endometriosis. Endocrinology 2007, 148:3814-3826.

30. Kitawaki J, Obayashi H, Ishihara H, Koshiba H, Kusuki I, Kado N, Tsukamoto K, Hasegawa G, Nakamura N, Honjo H: Oestrogen receptor-alpha gene polymorphism is associated with endometriosis, adenomyosis and leiomyomata. Hum Reprod 2001, 16:51-55.

31. Georgiou I, Syrrou M, Bouba I, Dalkalitsis N, Paschopoulos M, Navrozoglou I, Lolis D: Association of estrogen receptor gene polymorphisms with endometriosis. Fertil Steril 1999, 72:164-166.

32. Luisi S, Galleri L, Marini F, Ambrosini G, Brandi ML, Petraglia F: Estrogen receptor gene polymorphisms are associated with recurrence of endometriosis. Fertil Steril 2006, 85:764-766. 
33. Renner SP, Strick R, Oppelt P, Fasching PA, Engel S, Baumann R, Beckmann MW, Strissel PL: Evaluation of clinical parameters and estrogen receptor alpha gene polymorphisms for patients with endometriosis. Reproduction 2006, 131:153-161.

34. Huber A, Keck CC, Hefler LA, Schneeberger C, Huber JC, Bentz EK, Tempfer CB: Ten estrogen-related polymorphisms and endometriosis: a study of multiple gene-gene interactions. Obstet Gynecol 2005, 106:1025-1031.

35. Govindan S, Ahmad SN, Vedicherla B, Kodati V, Jahan P, Rao KP, Ahuja YR, Hasan Q: Association of progesterone receptor gene polymorphism (PROGINS) with endometriosis, uterine fibroids and breast cancer. Cancer Biomark 2007, 3:73-78.

36. Lattuada D, Somigliana E, Vigano P, Candiani M, Pardi G, Di Blasio AM: Genetics of endometriosis: a role for the progesterone receptor gene polymorphism PROGINS? Clin Endocrinol (Oxf) 2004, 61:190-194.

37. De Carvalho CV, Nogueira-De-Souza NC, Costa AM, Baracat EC, Girao MJ, D'Amora P, Schor E, da Silva ID: Genetic polymorphisms of cytochrome P450cl7alpha (CYP17) and progesterone receptor genes (PROGINS) in the assessment of endometriosis risk. Gynecol Endocrinol 2007, 23:29-33.

38. Wieser F, Schneeberger C, Tong D, Tempfer C, Huber JC, Wenzl R: PROGINS receptor gene polymorphism is associated with endometriosis. Fertil Steril 2002, 77:309-312.

39. Treloar SA, Zhao ZZ, Armitage T, Duffy DL, Wicks J, O'Connor DT, Martin NG, Montgomery GW: Association between polymorphisms in the progesterone receptor gene and endometriosis. Mol Hum Reprod 2005, 11:641-647

40. Lebovic DI, Mueller MD, Taylor RN: Immunobiology of endometriosis. Fertil Steril 2001, 75:1-10

41. Hsieh YY, Chang CC, Tsai FJ, Hsu Y, Tsai HD, Tsai CH: Polymorphisms for interleukin-4 (IL-4) -590 promoter, IL-4 intron3, and tumor necrosis factor alpha -308 promoter: non-association with endometriosis. J Clin Lab Anal 2002, 16:121-126.

42. Lee MK, Park AJ, Kim DH: Tumor necrosis factor-alpha and interleukin-6 promoter gene polymorphisms are not associated with an increased risk of endometriosis. Fertil Steril 2002, 77:1304-1305.

43. Wieser F, Fabjani G, Tempfer C, Schneeberger C, Zeillinger R, Huber JC, Wenz $\mathrm{R}$ : Tumor necrosis factor-alpha promotor polymorphisms and endometriosis. J Soc Gynecol Investig 2002, 9:313-318.

44. Montgomery GW, Nyholt DR, Zhao ZZ, Treloar SA, Painter JN, Missmer SA Kennedy SH, Zondervan KT: The search for genes contributing to endometriosis risk. Hum Reprod Update 2008, 14:447-457.

45. Rier SE, Martin DC, Bowman RE, Dmowski WP, Becker JL: Endometriosis in rhesus monkeys (Macaca mulatta) following chronic exposure to 2,3,7,8-tetrachlorodibenzo-p-dioxin. Fundam App/ Toxicol 1993, 21:433-441.

46. Mayani A, Barel S, Soback S, Almagor M: Dioxin concentrations in women with endometriosis. Hum Reprod 1997, 12:373-375.

47. Koninckx PR, Braet P, Kennedy SH, Barlow DH: Dioxin pollution and endometriosis in Belgium. Hum Reprod 1994, 9:1001-1002.

48. Hayes JD, Pulford DJ: The glutathione S-transferase supergene family: regulation of GST and the contribution of the isoenzymes to cancer chemoprotection and drug resistance. Crit Rev Biochem Mol Biol 1995, 30:445-600.

49. Guo SW: Glutathione S-transferases M1/T1 gene polymorphisms and endometriosis: a meta-analysis of genetic association studies. Mol Hum Reprod 2005, 11:729-743.

50. Hardy J, Singleton A: Genomewide association studies and human disease. N Engl J Med 2009, 360:1759-1768.

51. NHGRI: A Catalog of Published Genome-Wide Association Studies [http:// www.genome.gov/gwastudies]

52. Manolio TA, Brooks LD, Collins FS: A HapMap harvest of insights into the genetics of common disease. J Clin Invest 2008, 118:1590-1605.

53. McCarthy MI, Abecasis GR, Cardon LR, Goldstein DB, Little J, loannidis JP, Hirschhorn JN: Genome-wide association studies for complex traits: consensus, uncertainty and challenges. Nat Rev Genet 2008, 9:356-369.
54. Vigano P, Somigliana E, Vignali M, Busacca M, Blasio AM: Genetics of endometriosis: current status and prospects. Front Biosci 2007, 12:3247-3255

55. Templeman C, Marshall SF, Ursin G, Horn-Ross PL, Clarke CA, Allen M, Deapen D, Ziogas A, Reynolds P, Cress R, Anton-Culver H, West D, Ross RK, Bernstein L: Adenomyosis and endometriosis in the California Teachers Study. Fertil Steril 2008, 90:415-424

56. Missmer SA: Commentary: Endometriosis - epidemiologic considerations for a potentially 'high-risk' population. Int J Epidemio/ 2009, 38:1154-1155.

57. Missmer SA, Chavarro JE, Malspeis S, Bertone-Johnson ER, Hornstein MD, Spiegelman D, Barbieri RL, Willett WC, Hankinson SE: A prospective study of dietary fat consumption and endometriosis risk. Hum Reprod 2010, 25:1528-1535.

58. Weuve J, Hauser R, Calafat AM, Missmer SA, Wise LA: Association of exposure to phthalates with endometriosis and uterine leiomyomata: findings from NHANES, 1999-2004. Environ Health Perspect 2010, 118:825-832.

59. Kvaskoff M, Mesrine S, Clavel-Chapelon F, Boutron-Ruault MC: Endometriosis risk in relation to naevi, freckles and skin sensitivity to sun exposure: the French E3N cohort. Int J Epidemiol 2009, 38:1143-1153.

60. Treloar S, Hadfield R, Montgomery G, Lambert A, Wicks J, Barlow DH, O'Connor DT, Kennedy S: The International Endogene Study: a collection of families for genetic research in endometriosis. Fertil Steril 2002, 78:679-685.

61. Kennedy S: Is there a genetic basis to endometriosis? Semin Reprod Endocrinol 1997, 15:309-318.

62. Triendl R: Japan launches controversial Biobank project. Nat Med 2003 9:982.

63. Uno S, Zembutsu H, Hirasawa A, Takahashi A, Kubo M, Akahane T, Aoki D, Kamatani N, Hirata K, Nakamura Y: A genome-wide association study identifies genetic variants in the CDKN2BAS locus associated with endometriosis in Japanese. Nat Genet 2010, 42:707-710.

64. Gaetje R, Holtrich U, Engels K, Kissler S, Rody A, Karn T, Kaufmann M: Endometriosis may be generated by mimicking the ontogenetic development of the female genital tract. Fertil Steril 2007, 87:651-656.

65. Goumenou AG, Arvanitis DA, Matalliotakis IM, Koumantakis EE, Spandidos DA: Loss of heterozygosity in adenomyosis on hMSH2, hMLH1, p16Ink4 and GALT loci. Int J Mol Med 2000, 6:667-671.

66. Horne BD, Carlquist JF, Muhlestein JB, Bair TL, Anderson JL: Association of variation in the chromosome $9 \mathrm{p} 21$ locus with myocardial infarction versus chronic coronary artery disease. Circ Cardiovasc Genet 2008, 1:85-92.

67. Doria A, Wojcik J, Xu R, Gervino EV, Hauser TH, Johnstone MT, Nolan D, Hu FB, Warram JH: Interaction between poor glycemic control and 9p21 locus on risk of coronary artery disease in type 2 diabetes. JAMA 2008 , 300:2389-2397.

68. Yang XR, Liang X, Pfeiffer RM, Wheeler W, Maeder D, Burdette L, Yeager M, Chanock S, Tucker MA, Goldstein AM: Associations of 9p21 variants with cutaneous malignant melanoma, nevi, and pigmentation phenotypes in melanoma-prone families with and without CDNK2A mutations. Fam Cancer 2010, epub ahead of print.

69. Shete S, Kosking FJ, Robertson LB, Dobbins SE, Sanson M, Malmer B, Simon M, Marie Y, Boisselier B, Delattre JY, Hoang-Xuan K, El Hallani S, Idbaih A, Zelenika D, Andersson U, Henriksson R, Bergenheim AT, Feychting M, LonnS, Ahlborn A, Schramm J, Linnebank M, Hemminki K, Kumar R, Hepworth SJ, Price A, Armstrong G, Liu Y, Gu X, Yu R, Lau C, Schoemaker M, Muir K, Swerdlow A, Lathrop M, Bondy M, Houlston RS: Genome-wide association study identifies five susceptibility loci for glioma. Nat Genet 2009, 41:899-904

70. Varghese JS, Easton DF: Genome-wide association studies in common cancers - what have we learnt? Curr Opin Genet Dev 2010, 20:201-209.

doi:10.1186/gm196

Cite this article as: Dun C, et al:: Advances in the genetics of endometriosis. Genome Medicine 2010, 2:75 